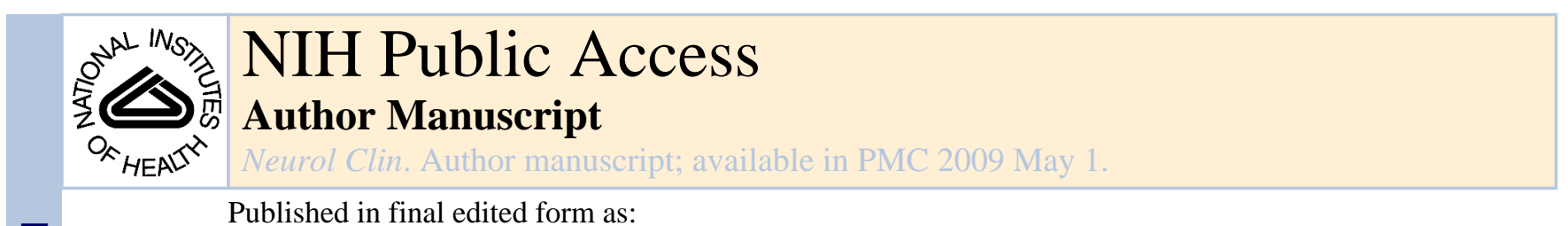

Published in final edited form as:

Neurol Clin. 2008 May ; 26(2): 521-541.

\title{
Management of Intracranial Hypertension
}

\author{
Leonardo Rangel-Castillo, MD, Shankar Gopinath, MD, and Claudia S. Robertson, MD* \\ Department of Neurosurgery, Baylor College of Medicine, One Baylor Plaza, Houston, TX 77030, \\ USA
}

\begin{abstract}
Effective management of intracranial hypertension involves meticulous avoidance of factors that precipitate or aggravate increased intracranial pressure. When intracranial pressure becomes elevated, it is important to rule out new mass lesions that should be surgically evacuated. Medical management of increased intracranial pressure should include sedation, drainage of cerebrospinal fluid, and osmotherapy with either mannitol or hypertonic saline. For intracranial hypertension refractory to initial medical management, barbiturate coma, hypothermia, or decompressive craniectomy should be considered. Steroids are not indicated and may be harmful in the treatment of intracranial hypertension resulting from traumatic brain injury.
\end{abstract}

Intracranial hypertension is a common neurologic complication in critically ill patients; it is the common pathway in the presentation of many neurologic and non-neurologic disorders. The underlying pathophysiology of increased intracranial pressure (ICP) is the subject of intense basic and clinical research, which has led to advances in understanding of the physiology related to ICP. Few specific treatment options for intracranial hypertension have been subjected to randomized trials, however, and most management recommendations are based on clinical experience.

\section{Intracranial pressure}

\section{Normal values}

In normal individuals with closed cranial fontanelles, central nervous system contents, including brain, spinal cord, blood, and cerebrospinal fluid (CSF), are encased in a noncompliant skull and vertebral canal, constituting a nearly incompressible system. There is a small amount of capacitance in the system provided by the intervertebral spaces. In the average adult, the skull encloses a total volume of $1450 \mathrm{~mL}: 1300 \mathrm{~mL}$ of brain, $65 \mathrm{~mL}$ of CSF, and $110 \mathrm{~mL}$ of blood [1]. The Monroe-Kellie hypothesis states the sum of the intracranial volumes of blood, brain, CSF, and other components is constant, and that an increase in any one of these must be offset by an equal decrease in another, or else pressure increases. An increase in pressure caused by an expanding intracranial volume is distributed evenly throughout the intracranial cavity $[2,3]$.

\footnotetext{
*Corresponding author. E-mail address: claudiar@bcm.tmc.edu (C.S. Robertson).

This PDF receipt will only be used as the basis for generating PubMed Central (PMC) documents. PMC documents will be made available for review after conversion (approx. 2-3 weeks time). Any corrections that need to be made will be done at that time. No materials will be released to PMC without the approval of an author. Only the PMC documents will appear on PubMed Central -- this PDF Receipt will not appear on PubMed Central.

Publisher's Disclaimer: This is a PDF file of an unedited manuscript that has been accepted for publication. As a service to our customers we are providing this early version of the manuscript. The manuscript will undergo copyediting, typesetting, and review of the resulting proof before it is published in its final citable form. Please note that during the production process errors may be discovered which could affect the content, and all legal disclaimers that apply to the journal pertain.
} 
The normal range for ICP varies with age. Values for pediatric subjects are not as well established. Normal values are less than 10 to $15 \mathrm{~mm} \mathrm{Hg}$ for adults and older children, 3 to 7 $\mathrm{mm} \mathrm{Hg}$ for young children, and 1.5 to $6 \mathrm{~mm} \mathrm{Hg}$ for term infants. ICP can be subatmospheric in newborns [4]. For the purpose of this article, normal adult ICP is defined as 5 to $15 \mathrm{~mm} \mathrm{Hg}$ (7.5-20 $\mathrm{cm} \mathrm{H}_{2} \mathrm{O}$ ). ICP values of 20 to $30 \mathrm{~mm} \mathrm{Hg}$ represent mild intracranial hypertension; however, when a temporal mass lesion is present, herniation can occur with ICP values less than $20 \mathrm{~mm} \mathrm{Hg}$ [5]. ICP values greater than 20 to $25 \mathrm{~mm} \mathrm{Hg}$ require treatment in most circumstances. Sustained ICP values of greater than $40 \mathrm{~mm} \mathrm{Hg}$ indicate severe, life-threatening intracranial hypertension.

\section{Cerebral dynamics overview}

Cerebral perfusion pressure (CPP) depends on mean systemic arterial pressure (MAP) and ICP by the following relationship:

CPP $=$ MAP - ICP

whereMAP $=(1 / 3$ systolicBP $)+(2 / 3$ diastolicBP $)$

As a result, CPP can be reduced from an increase in ICP, a decrease in blood pressure, or a combination of both factors. Through the normal regulatory process called pressure autoregulation, the brain is able to maintain a normal cerebral blood flow (CBF) with a CPP ranging from 50 to $150 \mathrm{~mm} \mathrm{Hg}$. At CPP values less than $50 \mathrm{~mm} \mathrm{Hg}$, the brain may not be able to compensate adequately, and CBF falls passively with CPP. After injury, the ability of the brain to pressure autoregulate may be absent or impaired, and even with a normal CPP, CBF can passively follow changes in CPP.

When CPP is within the normal autoregulatory range $(50-150 \mathrm{mmHg})$, this ability of the brain to pressure autoregulate also affects the response of ICP to a change in CPP [6-8]. When pressure autoregulation is intact, decreasing CPP results in vasodilation of cerebral vessels, which allows CBF to remain unchanged. This vasodilation can result in an increase in ICP, which further perpetuates the decrease in CPP. This response has been called the vasodilatory cascade. Likewise, an increase in CPP results in vasoconstriction of cerebral vessels and may reduce ICP. When pressure autoregulation is impaired or absent, ICP decreases and increases with changes in CPP.

\section{Intracranial hypertension}

\section{Causes of intracranial hypertension}

The different causes of intracranial hypertension (Box 1) can occur individually or in various combinations. In primary causes of increased ICP, normalization of ICP depends on rapidly addressing the underlying brain disorder. In the second group, intracranial hypertension is due to an extracranial or systemic process that is often remediable [9-11]. The last group is composed of the causes of increased ICP after a neurosurgical procedure.

\section{Box 1. Causes of intracranial hypertension}

Intracranial (primary)

Brain tumor

Trauma (epidural and subdural hematoma, cerebral contusions)

Nontraumatic intracerebral hemorrhage

Ischemic stroke

Hydrocephalus 


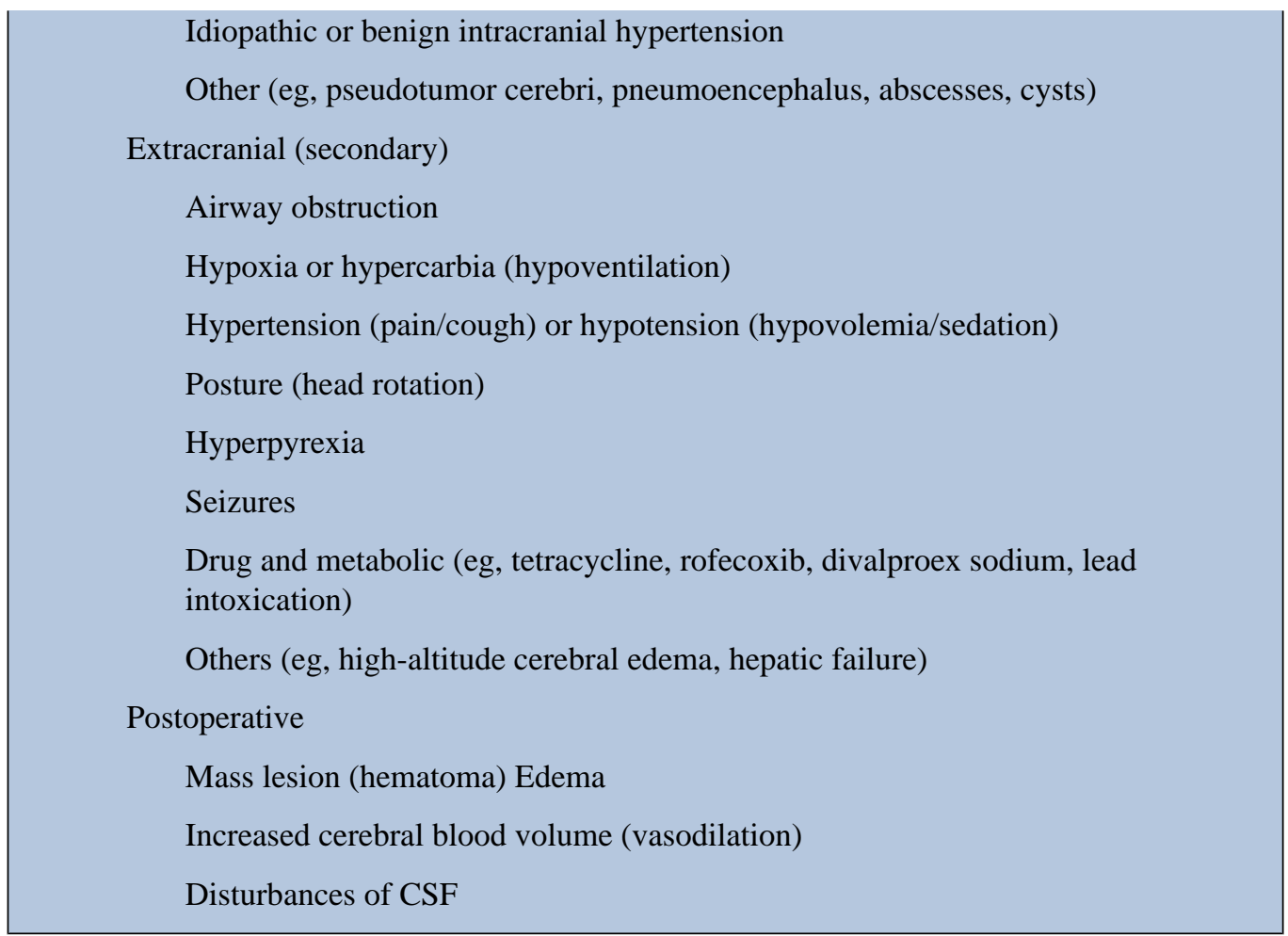

\section{Intracranial hypertension secondary to traumatic brain injury}

Special features should be considered in patients with traumatic brain injury (TBI), in which lesions may be heterogeneous, and several factors often contribute to increase the ICP [12]:

1. Traumatically induced masses: epidural or subdural hematomas, hemorrhagic contusions, foreign body, and depressed skull fractures

2. Cerebral edema [13]

3. Hyperemia owing to vasomotor paralysis or loss of autoregulation [14]

4. Hypoventilation that leads to hypercarbia with subsequent cerebral vasodilation

5. Hydrocephalus resulting from obstruction of the CSF pathways or its absorption

6. Increased intrathoracic or intra-abdominal pressure as a result of mechanical ventilation, posturing, agitation, or Valsalva maneuvers

After evacuation of traumatic mass lesions, the most important cause of increased ICP was thought to be vascular engorgement [14]. Recent studies have suggested that cerebral edema is the primary cause in most cases [15].

A secondary increase in the ICP often is observed 3 to 10 days after the trauma, principally as a result of a delayed hematoma formation, such as epidural hematomas, acute subdural hematoma, and traumatic hemorrhagic contusions with surrounding edema, sometimes requiring evacuation [16]. Other potential causes of delayed increases in ICP are cerebral vasospasm [17], hypoventilation, and hyponatremia.

\section{Neurologic intensive care monitoring}

Intracranial hypertension is an important cause of secondary injury in patients with acute neurologic and neurosurgical disorders and typically mandates specific monitoring. Patients 
with suspected intracranial hypertension, especially secondary to TBI, should have monitoring of ICP; monitoring of cerebral oxygen extraction, as with jugular bulb oximetry or brain tissue $\mathrm{PO}_{2}$, may also be indicated. Brain-injured patients also should have close monitoring of systemic parameters, including ventilation, oxygenation, electrocardiogram, heart rate, blood pressure, temperature, blood glucose, and fluid intake and output. Patients should be monitored routinely with pulse oximetry and capnography to avoid unrecognized hypoxemia and hypoventilation or hyperventilation. A central venous catheter commonly is needed to help evaluate volume status, and a Foley catheter is employed for accurate urine output.

\section{Intracranial pressure monitoring}

Clinical symptoms of increased ICP, such as headache, nausea, and vomiting, are impossible to elicit in comatose patients. Papilledema is a reliable sign of intracranial hypertension, but is uncommon after head injury, even in patients with documented elevated ICP. In a study of patients with head trauma, 54\% of patients had increased ICP, but only $3.5 \%$ had papilledema on fundoscopic examination [18]. Other signs, such as pupillary dilation and decerebrate posturing, can occur in the absence of intracranial hypertension. CT scan signs of brain swelling, such as midline shift and compressed basal cisterns, are predictive of increased ICP, but intracranial hypertension can occur without those findings [19].

\section{Types of monitors}

The ventriculostomy catheter is the preferred device for monitoring ICP and the standard against which all newer monitors are compared [20]. An intraventricular catheter is connected to an external pressure transducer via fluid-filled tubing. The advantages of the ventriculostomy are its relatively low cost, the option to use it for therapeutic CSF drainage, and its ability to recalibrate to minimize errors owing to measurement drift. The disadvantages are difficulties with insertion into compressed or displaced ventricles, inaccuracies of the pressure measurements because of obstruction of the fluid column, and the need to maintain the transducer at a fixed reference point relative to the patient's head. The system should be checked for proper functioning at least every 2 to 4 hours, and any time there is a change in the ICP, neurologic examination, and CSF output. This check should include assessing for the presence of an adequate waveform, which should have respiratory variations and transmitted pulse pressure.

When the ventricle cannot be cannulated, other alternatives can be used. Different non-fluidcoupled devices are available for ICP monitoring and have replaced the subarachnoid bolt. The microsensor transducer and the fiberoptic transducer are the most widely available. These transducer-tipped catheters can be inserted in the subdural space or directly into the brain tissue [21]. The main advantages of these monitors is the ease of insertion, especially in patients with compressed ventricles; however, none of the transducer-tipped catheters can be reset to zero after they are inserted into the skull, and they exhibit measurement drift over time [22]. Subdural and epidural monitors for ICP measurements are less accurate compared to ventriculostomy or parenchymal monitors.

For surgical patients, the ICP monitor may be inserted at the end of the surgical procedure. ICP monitoring is continued for as long as treatment of intracranial hypertension is required, typically 3 to 5 days. A secondary increase in ICP may be observed 3 to 10 days after trauma in $30 \%$ of patients with intracranial hypertension [16] secondary to development of delayed intracerebral hematoma, cerebral vasospasm, or systemic factors such as hypoxia and hypotension. 


\section{Types of intracranial pressure waveforms}

The variations seen in the normal tracing of ICP originate from small pulsations transmitted from the systemic blood pressure to the intracranial cavity. These blood pressure pulsations are superimposed on slower oscillation caused by the respiratory cycle. In mechanically ventilated patients, the pressure in the superior vena cava increases during inspiration, which reduces venous outflow from the cranium, causing an elevation in ICP.

\section{Pathologic waveforms}

As the ICP increases, cerebral compliance decreases, arterial pulses become more pronounced, and venous components disappear. Pathologic waveforms include Lundberg A, B, and C types. Lundberg A waves or plateau waves are ICP elevations to more than $50 \mathrm{~mm} \mathrm{Hg}$ lasting 5 to 20 minutes. These waves are accompanied by a simultaneous increase in MAP, but it is not clearly understood if the change in MAP is cause or effect. Lundberg B waves or pressure pulses have an amplitude of $50 \mathrm{~mm} \mathrm{Hg}$ and occur every 30 seconds to 2 minutes. Lundberg $\mathrm{C}$ waves have an amplitude of $20 \mathrm{~mm} \mathrm{Hg}$ and a frequency of 4 to 8 per minute; they are seen in the normal ICP waveform, but high-amplitude $\mathrm{C}$ waves may be superimposed on plateau waves [23].

\section{Indications for intracranial pressure monitoring}

Monitoring of ICP is an invasive technique and has some associated risks. For a favorable riskto-benefit ratio, ICP monitoring is indicated only in patients with significant risk of intracranial hypertension [12] (Box 2). Patients with TBI who are particularly at risk for developing an elevated ICP include those with Glasgow Coma Scale of 8 or less after cardiopulmonary resuscitation and who have an abnormal admission head CT scan. Such abnormalities might include low-density or high-density lesions, including contusions; epidural, subdural, or intraparenchymal hematomas; compression of basal cisterns; and edema [24]. Patients who are able to follow commands have a low risk for developing intracranial hypertension, and serial neurologic examinations can be followed.

\section{Box 2: Indications for ICP Monitoring}

GCS Score: 3-8 (after resuscitation)

1. Abnormal Admission Head CT Scan
a. Hematoma
b. Contusion
c. Edema
d. Herniation
e. Compressed basal cisterns

2. Normal Admission Head CT Scan PLUS 2 or more of the following
a. Age $>40$ years
b. Motor posturing
c. Systolic blood pressure $<90 \mathrm{~mm} \mathrm{Hg}$

Although CT scan findings are not accurate in determining the actual ICP, the risk of developing intracranial hypertension can be predicted. Sixty percent of patients with closed head injury and an abnormal CT scan have intracranial hypertension. Only 13\% of patients 
with a normal CT scan have elevated ICP except for patients with certain risk factors, including age greater than 40 years old, systolic blood pressure less than $90 \mathrm{~mm} \mathrm{Hg}$, and decerebrate or decorticate posturing on motor examination. Patients with a normal CT scan have $60 \%$ risk of intracranial hypertension if they have two risk factors and $4 \%$ if they have only one risk factor. Patients with a Glasgow Coma Scale score greater than 8 also might be considered for ICP monitoring if they require treatment that would not allow serial neurologic examinations, such as prolonged anesthesia for surgery of multiple injuries or prolonged pharmacologic paralysis for ventilatory management, or if they require a treatment that might increase ICP, such as positive end-expiratory pressure (PEEP). Other, less common indications include patients with multiple systemic injuries with altered level of consciousness and subsequent to removal of an intracranial mass (eg, hematoma, tumor) [12]. ICP monitoring also must be considered in nontraumatic conditions in which an intracranial mass lesion is present (eg, cerebral infarction, spontaneous intracerebral hemorrhage) and has a likelihood of expansion leading to intracranial hypertension and clinical deterioration. The duration of monitoring is until ICP has been normal for 24 to 48 hours without ICP therapy.

\section{Complications of intracranial pressure monitoring}

The most common complication of ventriculostomy catheter placement is infection with an incidence of $5 \%$ to $14 \%$; colonization of the device is more common than clinical infection [25]. A study found no significant reduction in infection rate in patients undergoing prophylactic change of monitors before day 5, compared with those whose catheters were in place for 5 days or more.[26]. Factors that are not associated with infection are insertion of the catheter in the neurologic ICU, previous catheter insertion, drainage of CSF, and use of steroids. In a group of patients with prolonged ventricular drainage of 10 days or more, a non-linear increase in daily infection rate was observed over the initial 4 days but remained constant despite prolonged catheter use [27]. Use of antibiotic-coated ventriculostomy catheters has been shown to reduce the risk of infection from $9.4 \%$ to $1.3 \%$ [28]. Other complications of ventriculostomy catheters are hemorrhage with an overall incidence of $1.4 \%$, malfunction, obstruction, and malposition.

\section{Intracranial pressure treatment measures: brief summary of goals of therapy}

1. Maintain ICP at less than 20 to $25 \mathrm{~mm} \mathrm{Hg}$.

2. Maintain CPP at greater than $60 \mathrm{~mm} \mathrm{Hg}$ by maintaining adequate MAP.

3. Avoid factors that aggravate or precipitate elevated ICP.

An overall approach to the management of intracranial hypertension is presented in Fig. 1.

\section{General care to minimize intracranial hypertension}

Prevention or treatment of factors that may aggravate or precipitate intracranial hypertension is a cornerstone of neurologic critical care. Specific factors that may aggravate intracranial hypertension include obstruction of venous return (head position, agitation), respiratory problems (airway obstruction, hypoxia, hypercapnia), fever, severe hypertension, hyponatremia, anemia, and seizures.

\section{Optimizing cerebral venous outflow}

To minimize venous outflow resistance and promote displacement of CSF from the intracranial compartment to the spinal compartment, elevation of the head of the bed and keeping the head in a neutral position are standards in neurosurgical care. Some authors have advocated keeping the patient's head flat to maximize CPP [7]. Other studies have shown a reduction in ICP without a reduction in either CPP or CBF in most patients with elevation of the head to $30^{\circ}$ 
[29]. Still other authors have observed that elevation of the head to $30^{\circ}$ reduced ICP and increased CPP, but did not change brain tissue oxygenation [30]. The reduction in ICP afforded by $15^{\circ}$ to $30^{\circ}$ of head elevation is probably advantageous and safe for most patients. When head elevation is used, the pressure transducers for blood pressure and ICP must be zeroed at the same level (at the level of the foramen of Monro) to assess CPP accurately.

Increased intra-abdominal pressure, as can occur with abdominal compartment syndrome, also can exacerbate ICP presumably by obstructing cerebral venous outflow. Several case reports have observed immediate reductions in ICP with decompressive laparotomy in such circumstances. A retrospective report indicated that even when abdominal compartment syndrome is not present, abdominal fascial release can reduce effectively ICP that is refractory to medical treatment [31].

\section{Respiratory failure}

Respiratory dysfunction is common in patients with intracranial hypertension, especially when the cause is head trauma. Hypoxia and hypercapnia can increase ICP dramatically, and mechanical ventilation can alter cerebral hemodynamics. Optimal respiratory management is crucial for control of ICP.

Thirty-six percent of comatose head injury patients present with hypoxia and respiratory dysfunction requiring mechanical ventilation on admission. Pneumonia and pulmonary insufficiency occur in $42 \%$ and $28 \%$ as complications during hospitalization. In 227 spontaneously breathing patients with neurologic disorders, most with intracranial hypertension, North and Jennett found that $60 \%$ had breathing abnormalities, including periodic respirations, tachypnea, and irregular breathing [32]. Periodic breathing was not correlated, however, with any particular anatomic site of the neurologic injury. Periodic episodes of hypoventilation can precipitate increased ICP [33]. Controlled ventilation to maintain a normal $\mathrm{PaCO}_{2}$ can eliminate this cause of intracranial hypertension.

Mechanical ventilation also can have adverse effects on ICP. PEEP, which may be needed to improve oxygenation, can increase ICP by impeding venous return and increasing cerebral venous pressure and ICP, and by decreasing blood pressure leading to a reflex increase of cerebral blood volume. For PEEP to increase cerebral venous pressure to levels that would increase ICP, the cerebral venous pressure must at least equal the ICP. The higher the ICP, the higher the PEEP must be to have such a direct hydraulic effect on ICP. The consequences of PEEP on ICP also depend on lung compliance, and minimal consequences for ICP usually are observed when lung compliance is low as in patients with acute lung injury [34].

\section{Sedation and analgesia}

Agitation and pain may significantly increase blood pressure and ICP. Adequate sedation and analgesia is an important adjunct treatment. No sedative regimen has clear advantages in this patient population. In general, benzodiazepines cause a coupled reduction in cerebral metabolic rate of oxygen $\left(\mathrm{CMRO}_{2}\right)$ and $\mathrm{CBF}$, with no effect on ICP, whereas the narcotics have no effect on $\mathrm{CMRO}_{2}$ or $\mathrm{CBF}$, but have been reported to increase ICP in some patients [35]. One consideration in the choice of sedative should be to minimize effects on blood pressure because most available agents can decrease blood pressure. Hypovolemia predisposes to hypotensive side effects and should be treated before administering sedative agents. Selection of shorter acting agents may have the advantage of allowing brief interruption of sedation to evaluate neurologic status. 


\section{Fever}

Fever increases metabolic rate by $10 \%$ to $13 \%$ per degree Celsius and is a potent vasodilator. Fever-induced dilation of cerebral vessels can increase CBF and may increase ICP. Fever during the postinjury period worsens neurologic injury in experimental models of TBI [36]. In an observational study in patients with TBI, Jones and colleagues [37] found a significant relationship between fever and a poor neurologic outcome. While a patient is at risk for intracranial hypertension, fever should be controlled with antipyretics and cooling blankets. Infectious causes must be sought and treated with appropriate antibiotics when present.

\section{Hypertension}

Elevated blood pressure is seen commonly in patients with intracranial hypertension, especially secondary to head injury, and is characterized by a systolic blood pressure increase greater than diastolic increase. It is associated with sympathetic hyperactivity [38]. It is unwise to reduce systemic blood pressure in patients with hypertension associated with untreated intracranial mass lesions because cerebral perfusion is being maintained by the higher blood pressure. In the absence of an intracranial mass lesion, the decision to treat systemic hypertension is more controversial and may need to be individualized for each patient.

When pressure autoregulation is impaired, which is common after TBI, systemic hypertension may increase CBF and ICP. In addition, elevated blood pressure may exacerbate cerebral edema and increase the risk of postoperative intracranial hemorrhage.

Systemic hypertension may resolve with sedation. If the decision is made to treat systemic hypertension, the choice of antihypertensive agent is important. Vasodilating drugs, such as nitroprusside, nitroglycerin, and nifedipine, can be expected to increase ICP and may reflexively increase plasma catecholamines, which may be deleterious to the marginally perfused injured brain. Sympathomimetic-blocking antihypertensive drugs, such as $\beta$-blocking drugs (labetalol, esmolol) or central acting $\alpha$-receptor agonists (clonidine), are preferred because they reduce blood pressure without affecting the ICP. Agents with a short half-life have an advantage when the blood pressure is labile.

\section{Treatment of anemia}

Anecdotal cases have been reported of patients with severe anemia presenting with symptoms of increased ICP and signs of papilledema, which resolve with treatment of the anemia [39]. The mechanism is thought to be related to the marked increase in CBF that is required to maintain cerebral oxygen delivery when anemia is severe. Although anemia has not been clearly shown to exacerbate ICP after TBI, a common practice is to maintain hemoglobin concentration at a minimum of $10 \mathrm{~g} / \mathrm{dL}$. In view of a large randomized trial of critically ill patients that showed better outcome with a more restrictive transfusion threshold of $7 \mathrm{~g} / \mathrm{dL}$ [40], the issue of optimal hemoglobin concentration in patients with TBI needs further study.

\section{Prevention of seizures}

The risk of seizures after trauma is related to the severity of the brain injury; seizures occur in $15 \%$ to $20 \%$ of patients with severe head injury. Seizures can increase cerebral metabolic rate and ICP, but there is no clear relationship between the occurrence of early seizures and a worse neurologic outcome [41]. In patients with severe TBI, 50\% of seizures may be subclinical and can be detected only with continuous electroencephalographic monitoring [42]. Significant risk factors for later seizures are brain contusions, subdural hematoma, depressed skull fracture, penetrating head wound, loss of consciousness or amnesia for more than 1 day, and age 65 years or older. 
In a randomized clinical trial, phenytoin reduced the incidence of seizures during the first week after trauma, but not thereafter [43]. Based on this study, seizure prophylaxis for patients with severe brain injury is recommended for the first 7 days after injury. Treatment with anticonvulsants beyond 7 days should be reserved for patients who develop late seizures [44].

\section{Measures for refractory intracranial hypertension}

For patients with sustained ICP elevations of greater than 20 to $25 \mathrm{~mm} \mathrm{Hg}$, additional measures are needed to control the ICP. Emergent surgical management should be considered whenever intracranial hypertension occurs suddenly or is refractory to medical management.

\section{Medical interventions}

\section{Heavy sedation and paralysis}

Routine paralysis of patients with neurosurgical disorders is not indicated; however, intracranial hypertension caused by agitation, posturing, or coughing can be prevented by sedation and nondepolarizing muscle relaxants that do not alter cerebrovascular resistance [45]. A commonly used regimen is morphine and lorazepam for analgesia/sedation and cisatracurium or vecuronium as a muscle relaxant, with the dose titrated by twitch response to stimulation. Although a disadvantage of this therapy is that the neurologic examination cannot be monitored closely, the sedatives and muscle relaxants can be interrupted once a day, usually before morning rounds, to allow neurologic assessments.

Major complications of neuromuscular blockade are myopathy, polyneuropathy, and prolonged neuromuscular blockade. Myopathy is associated with the use of neuromuscular blocking agents, particularly in combination with corticosteroids [46]. Polyneuropathy has been observed in patients with sepsis and multiple organ failure. Prolonged neuromuscular blockade is seen in patients with multiple organ failure especially with kidney and liver dysfunction. Recommendations to minimize these complications are limiting the use and dose of neuromuscular blocking agents, train-of-four monitoring, measuring creatine phosphokinase daily, and stopping the drug daily to evaluate motor response [47].

\section{Hyperosmolar therapy}

Mannitol is the most commonly used hyperosmolar agent for the treatment of intracranial hypertension. More recently, hypertonic saline also has been used in this circumstance. A few studies have compared the relative effectiveness of these two hyperosmotic agents, but more work is needed.

Intravenous bolus administration of mannitol lowers the ICP in 1 to 5 minutes with a peak effect at 20 to 60 minutes. The effect of mannitol on ICP lasts 1.5 to 6 hours, depending on the clinical condition [48]. Mannitol usually is given as a bolus of $0.25 \mathrm{~g} / \mathrm{kg} \mathrm{to} 1 \mathrm{~g} / \mathrm{kg}$ body weight; when urgent reduction of ICP is needed, an initial dose of $1 \mathrm{~g} / \mathrm{kg}$ body weight should be given. Arterial hypotension (systolic blood pressure $<90 \mathrm{~mm} \mathrm{Hg}$ ) should be avoided. Two prospective clinical trials, one in patients with subdural hematoma and the other in patients who have herniated from diffuse brain swelling, have suggested that a higher dose of mannitol $(1.4 \mathrm{~g} / \mathrm{kg})$ may give significantly better results in these extremely critical situations than lower doses of mannitol [49,50]. When long-term reduction of ICP is needed, 0.25 to $0.5 \mathrm{~g} / \mathrm{kg}$ can be repeated every 2 to 6 hours Attention should be paid to replacing fluid that is lost because of mannitol-induced diuresis, or else intravascular volume depletion results.

Mannitol has rheologic and osmotic effects. Immediately after infusion of mannitol, there is an expansion of plasma volume and a reduction in hematocrit and in blood viscosity, which may increase $\mathrm{CBF}$ and on balance increase oxygen delivery to the brain. These rheologic effects 
of mannitol depend on the status of pressure autoregulation [51]. In patients with intact pressure autoregulation, infusion of mannitol induces cerebral vasoconstriction, which maintains CBF constant, and the decrease in ICP is large. In patients with absent pressure autoregulation, infusion of mannitol increases CBF, and the decrease in ICP is less pronounced. Mannitol also may improve microcirculatory rheology [50] and has free radical scavenging effects.

The osmotic effect of mannitol increases serum tonicity, which draws edema fluid from cerebral parenchyma. This process takes 15 to 30 minutes until gradients are established. Serum osmolarity seems to be optimal when increased to 300 to $320 \mathrm{mOsm}$ and should be kept at less than $320 \mathrm{mOsm}$ to avoid side effects of therapy, such as hypovolemia, hyperosmolarity, and renal failure. Mannitol opens the blood-brain barrier, and mannitol that has crossed the bloodbrain barrier may draw fluid into the central nervous system, which can aggravate vasogenic edema. For this reason, when it is time to stop mannitol, it should be tapered to prevent a rebound in cerebral edema and ICP. The adverse effects of mannitol are most likely when mannitol is present in the circulation for extended periods, such as in slow or continuous infusions or with repeated administration of higher than necessary doses.

Hypertonic saline, given in concentrations ranging from $3 \%$ to $23.4 \%$, also creates an osmotic force to draw water from the interstitial space of the brain parenchyma into the intravascular compartment in the presence of an intact blood-brain barrier, reducing intracranial volume and ICP. In some studies, hypertonic saline has been more effective at reducing ICP than mannitol $[52,53]$. Hypertonic saline has a clear advantage over mannitol in hypovolemic and hypotensive patients. Mannitol is relatively contraindicated in hypovolemic patients because of the diuretic effects, whereas hypertonic saline augments intravascular volume and may increase blood pressure in addition to decreasing ICP. Hypertonic saline was not associated with improved neurologic outcomes, however, when given as a prehospital bolus to hypotensive patients with severe TBI [54]. Adverse effects of hypertonic saline administration include hematologic and electrolyte abnormalities, such as bleeding secondary to decreased platelet aggregation and prolonged coagulation times, hypokalemia, and hyperchloremic acidosis [55]. Hyponatremia should be excluded before administering hypertonic saline to reduce the risk of central pontine myelinolysis.[56].

\section{Hyperventilation}

Hyperventilation decreases $\mathrm{PaCO}_{2}$, which can induce constriction of cerebral arteries by alkalinizing the CSF. The resulting reduction in cerebral blood volume decreases ICP. Hyperventilation has limited use in the management of intracranial hypertension, however, because this effect on ICP is time limited, and because hyperventilation may produce a sufficient decrease in CBF to induce ischemia.

The vasoconstrictive effect on cerebral arterioles lasts only 11 to 20 hours because the $\mathrm{pH}$ of the CSF rapidly equilibrates to the new $\mathrm{PaCO}_{2}$ level. As the CSF pH equilibrates, the cerebral arterioles redilate, possibly to a larger caliber than at baseline, and the initial reduction in cerebral blood volume comes at the cost of a possible rebound phase of increased ICP [57, 58]. For this reason, the most effective use of hyperventilation is acutely to allow time for other, more definitive treatments to be put into action. When hypocarbia is induced and maintained for several hours, it should be reversed slowly, over several days, to minimize this rebound hyperemia [59].

Hyperventilation decreases CBF, but whether this reduction in flow is sufficient to induce ischemia in injured brain is controversial. One prospective study showed that acutely reducing $\mathrm{PaCO}_{2}$ from an average of $36 \mathrm{~mm} \mathrm{Hg}$ to $29 \mathrm{~mm} \mathrm{Hg}$ reduced global CBF and significantly increased the volume of brain that was markedly hypoperfused despite improvements in ICP and CPP [60]. Diringer and coworkers [61] showed similar changes in CBF with moderate 
hyperventilation, but did not observe any changes in regional $\mathrm{CMRO}_{2}$ even when $\mathrm{CBF}$ was reduced to less than $10 \mathrm{~mL} / 100 \mathrm{~g} / \mathrm{min}$ in injured brain tissue, suggesting that energy failure associated with cerebral ischemia was not occurring.

Although hyperventilation-induced ischemia has not been clearly shown, routine chronic hyperventilation (to $\mathrm{PaCO}_{2}$ of $20-25 \mathrm{~mm} \mathrm{Hg}$ ) had a detrimental effect on outcome in one randomized clinical trial [59]. The authors of this study recommended using hyperventilation only in patients with intracranial hypertension, rather than as a routine in all head-injured patients. This view is reinforced in TBI guidelines.

\section{Barbiturate coma}

Barbiturate coma should only be considered for patients with refractory intracranial hypertension because of the serious complications associated with high-dose barbiturates, and because the neurologic examination becomes unavailable for several days [62]. Pentobarbital is given in a loading dose of $10 \mathrm{mg} / \mathrm{kg}$ body weight followed by $5 \mathrm{mg} / \mathrm{kg}$ body weight each hour for 3 doses. The maintenance dose is 1 to $2 \mathrm{mg} / \mathrm{kg} / \mathrm{h}$, titrated to a serum level of 30 to 50 $\mu \mathrm{g} / \mathrm{mL}$ or until the electroencephalogram shows a burst suppression pattern. Although routine use of barbiturates in unselected patients has not been consistently effective in reducing morbidity or mortality after severe head injury [63,64], a randomized multicenter trial showed that instituting barbiturate coma in patients with refractory intracranial hypertension resulted in a twofold greater chance of controlling the ICP [65].

The mechanism of ICP reduction by barbiturates is unclear, but likely reflects a coupled reduction in $\mathrm{CBF}$ and $\mathrm{CMRO}_{2}$, with an immediate effect on ICP. Studies by Messeter and colleagues $[66,67]$ have suggested that the reduction in ICP with barbiturates is closely tied to the retention of carbon dioxide reactivity by the brain. Complications occurring during treatment with barbiturate coma include hypotension in $58 \%$ of patients, hypokalemia in $82 \%$, respiratory complications in $76 \%$, infections in 55\%, hepatic dysfunction in $87 \%$, and renal dysfunction in $47 \%$ [68]. Hypotension caused by pentobarbital should be treated first with volume replacement and then with vasopressors if necessary. Experimental studies suggest that for the treatment of hypotension associated with barbiturate coma, volume resuscitation may be better than dopamine [69] because dopamine infusion increased cerebral metabolic requirements and partially offset the beneficial effects of barbiturates on $\mathrm{CMRO}_{2}$.

\section{Hypothermia}

Although a multicenter randomized clinical trial of moderate hypothermia in severe TBI did not show a beneficial effect on neurologic outcome, it was noted that fewer patients randomized to moderate hypothermia had intracranial hypertension [70]. A pilot randomized clinical trial of hypothermia in children with TBI produced similar findings-no improvement in neurologic outcome, but a reduction in ICP during the hypothermia treatment [71]. Although routine induction of hypothermia is not indicated at present, hypothermia may be an effective adjunctive treatment for increased ICP refractory to other medical management.

\section{Steroids}

Steroids commonly are used for primary and metastastic brain tumors, to decrease vasogenic cerebral edema. Focal neurologic signs and decreased mental status owing to surrounding edema typically begin to improve within hours [72]. Increased ICP, when present, decreases over the following 2 to 5 days, in some cases to normal. The most commonly used regimen is intravenous dexamethasone, $4 \mathrm{mg}$ every 6 hours. For other neurosurgical disorders, such as TBI or spontaneous intracerebral hemorrhage, steroids have not been shown to have a benefit $[73,74]$ and in some studies have had a detrimental effect [75,76]. 
The CRASH trial [75] is a recently completed, large ( $>10,000$ patients enrolled), placebocontrolled randomized clinical trial of methylprednisolone for 48 hours in patients with TBI. Administration of methylprednisolone resulted in a significant increase in the risk of death from $22.3 \%$ to $25.7 \%$ (relative risk $1.15,95 \%$ confidence interval $1.07-1.24$ ). This trial confirmed previous studies and guidelines that routine administration of steroids is not indicated for patients with TBI.

\section{Surgical interventions}

\section{Resection of mass lesions}

Intracranial masses producing elevated ICP should be removed when possible. Acute epidural and subdural hematomas are a hyperacute surgical emergency, especially epidural hematoma because the bleeding is under arterial pressure. Brain abscess must be drained, and pneumocephalus must be evacuated if it is under sufficient tension to increase ICP. Surgical management of spontaneous intracerebral bleeding is controversial [77].

\section{Cerebrospinal fluid drainage}

CSF drainage lowers ICP immediately by reducing intracranial volume and more long-term by allowing edema fluid to drain into the ventricular system. Drainage of even a small volume of CSF can lower ICP significantly, especially when intracranial compliance is reduced by injury. This modality can be an important adjunct therapy for lowering ICP. If the brain is diffusely swollen, the ventricles may collapse, and this modality then has limited utility.

\section{Decompressive craniectomy}

The surgical removal of part of the calvaria to create a window in the cranial vault is the most radical intervention for intracranial hypertension, negating the Monro-Kellie doctrine of fixed intracranial volume and allowing for herniation of swollen brain through the bone window to relieve pressure. Decompressive craniectomy has been used to treat uncontrolled intracranial hypertension of various origins, including cerebral infarction [78], trauma, subarachnoid hemorrhage, and spontaneous hemorrhage. Patient selection, timing of operation, type of surgery, and severity of clinical and radiologic brain injury all are factors that determine the outcome of this procedure.

Sahuquillo and Arikan [79] reviewed the evidence in the literature for studies evaluating the effectiveness of decompressive craniectomy after TBI. They found only one small randomized clinical trial in 27 children with TBI [80]. This trial found a reduced risk ratio for death of 0.54 (95\% confidence interval 0.17-1.72), and a risk ratio of 0.54 for death, vegetative status, or severe disability 6 to 12 months after injury (95\% confidence interval $0.29-1.07$ ). All of the available studies in adults are either case series or cohorts with historical controls. These reports suggest that decompressive craniectomy effectively reduces ICP in most (85\%) patients with intracranial hypertension refractory to conventional medical treatment $[81,82]$. Brain oxygenation measured by tissue $\mathrm{PO}_{2}$ and blood flow estimated by middle cerebral artery flow velocity also are usually improved after decompressive craniectomy [83,84]. Reported complications include hydrocephalus, hemorrhagic swelling ipsilateral to the craniectomy site, and subdural hygroma [81]. A case report of paradoxical herniation also has been reported after a lumbar puncture in a patient with a decompressive craniectomy [85].

There are limited results from randomized trials to confirm or refute the effectiveness of decompressive craniectomy in adults. Reports suggest, however, that decompressive craniectomy may be a useful option when maximal medical treatment has failed to control ICP. There are ongoing randomized controlled trials in TBI (Rescue ICP [86] and DECRAN). In a pooled analysis of randomized trials in patients with malignant MCA infarction, decompressive 
surgery undertaken within $48 \mathrm{~h}$ of stroke was associated with reduced mortality and an increased proportion of patients with a favourable functional outcome [87].

\section{Summary}

Effective treatment of intracranial hypertension involves meticulous avoidance of factors that precipitate or aggravate increased ICP. When ICP becomes elevated, it is important to rule out new mass lesions that should be surgically evacuated. Medical management of increased ICP should include sedation, drainage of CSF, and osmotherapy with either mannitol or hypertonic saline. For intracranial hypertension refractory to initial medical management, barbiturate coma, hypothermia, or decompressive craniectomy should be considered. Steroids are not indicated and may be harmful in the treatment of intracranial hypertension resulting from TBI.

\section{Acknowledgements}

This article was supported by NIH grant P01-NS38660.

\section{References}

1. Doczi T. Volume regulation of the brain tissue-a survey. Acta Neurochir (Wien) 1993;121:1-8. [PubMed: 8475800]

2. Langfitt TW, Weinstein JD, Kassell NF. Cerebral vasomotor paralysis produced by intracranial hypertension. Neurology 1965;15:622-41. [PubMed: 14306322]

3. Miller JD, Sullivan HG. Severe intracranial hypertension. Int Anesthesiol Clin 1979;17:19-75. [PubMed: 387614]

4. Welch K. The intracranial pressure in infants. J Neurosurg 1980;52:693-9. [PubMed: 7373397]

5. Andrews BT, Chiles BW III, Oslen WL, et al. The effect of intracerebral hematoma location on the risk of brain stem compression and on clinical outcome. J Neurosurg 1988;69:518-22. [PubMed: 3418383]

6. Hlatky R, Valadka A, Robertson CS. Prediction of a response in ICP to induced hypertension using dynamic testing of cerebral pressure autoregulation. J Neurotrauma 2004;21:1152.

7. Rosner MJ, Coley IB. Cerebral perfusion pressure, intracranial pressure, and head elevation. J Neurosurg 1986;65:636-41. [PubMed: 3772451]

8. Gobiet W, Grote W, Bock WJ. The relation between intracranial pressure, mean arterial pressure and cerebral blood flow in patients with severe head injury. Acta Neurochir (Wien) 1975;32:13-24. [PubMed: 1163313]

9. Friedman DI. Medication-induced intracranial hypertension in dermatology. Am J Clin Dermatol 2005;6:29-37. [PubMed: 15675888]

10. Jacob S, Rajabally YA. Intracranial hypertension induced by rofecoxib. Headache 2005;45:75-6. [PubMed: 15663617]

11. Digre K, Warner J. Is vitamin A implicated in the pathophysiology of increased intracranial pressure? Neurology 2005;64:1827. [PubMed: 15962400]

12. Adelson PD, Bratton SL, Carney NA, et al. Guidelines for the acute medical management of severe traumatic brain injury in infants, children, and adolescents: Chapter 5. indications for intracranial pressure monitoring in pediatric patients with severe traumatic brain injury. Pediatr Crit Care Med 2003;4:S19-24. [PubMed: 12847341]

13. Asgeirsson B, Grande PO, Nordstrom CH. A new therapy of post-trauma brain oedema based on haemodynamic principles for brain volume regulation. Intensive Care Med 1994;20:260-7. [PubMed: 8046119]

14. Bruce DA, Alavi A, Bilaniuk L, et al. Diffuse cerebral swelling following head injuries in children: the syndrome of "malignant brain edema". J Neurosurg 1981;54:170-8. [PubMed: 7452330]

15. Marmarou A, Fatouros PP, Barzo P, et al. Contribution of edema and cerebral blood volume to traumatic brain swelling in head-injured patients. J Neurosurg 2000;93:183-93. [PubMed: 10930002] 
16. Unterberg A, Kiening K, Schmiedek P, et al. Long-term observations of intracranial pressure after severe head injury: the phenomenon of secondary rise of intracranial pressure. Neurosurgery 1993;32:17-23. [PubMed: 8421552]

17. Taneda M, Kataoka K, Akai F, et al. Traumatic subarachnoid hemorrhage as a predictable indicator of delayed ischemic symptoms. J Neurosurg 1996;84:762-8. [PubMed: 8622149]

18. Selhorst JB, Gudeman SK, Butterworth JF, et al. Papilledema after acute head injury. Neurosurgery 1985;16:357-63. [PubMed: 3982615]

19. Kishore PR, Lipper MH, Becker DP, et al. Significance of CT in head injury: correlation with intracranial pressure. AJR Am J Roentgenol 1981;137:829-33. [PubMed: 6974981]

20. Adelson PD, Bratton SL, Carney NA, et al. Guidelines for the acute medical management of severe traumatic brain injury in infants, children, and adolescents: Chapter 7 intracranial pressure monitoring technology. Pediatr Crit Care Med 2003;4:S28-30. [PubMed: 12847343]

21. Gopinath SP, Robertson CS, Contant CF, et al. Clinical evaluation of a miniature strain-gauge transducer for monitoring intracranial pressure. Neurosurgery 1995;36:1137-40. [PubMed: 7643993]

22. Czosnyka M, Czosnyka Z, Pickard JD. Laboratory testing of three intracranial pressure microtransducers: technical report. Neurosurgery 1996;38:219-24. [PubMed: 8747977]

23. Lundberg N. Continuous recording and control of ventricular fluid pressure in neurosurgical practice. Acta Psychiatr Scand 1960;36(Suppl 149):1-193.

24. O’Sullivan MG, Statham PF, Jones PA, et al. Role of intracranial pressure monitoring in severely head-injured patients without signs of intracranial hypertension on initial computerized tomography. J Neurosurg 1994;80:46-50. [PubMed: 8271021]

25. Mayhall CG, Archer NH, Lamb VA, et al. Ventriculostomy-related infections: a prospective epidemiologic study. N Engl J Med 1984;310:553-9. [PubMed: 6694707]

26. Holloway KL, Barnes T, Choi S, et al. Ventriculostomy infections: the effect of monitoring duration and catheter exchange in 584 patients. J Neurosurg 1996;85:419-424. [PubMed: 8751626]

27. Park P, Garton HJL, Kocan MJ, et al. Risk of Infection with Prolonged Ventricular Catheterization. Neurosurgery 2004;55:594-601. [PubMed: 15335426]

28. Zabramski JM, Whiting D, Darouiche RO, et al. Efficacy of antimicrobial-impregnated external ventricular drain catheters: a prospective, randomized, controlled trial. J Neurosurg 2003;98:72530. [PubMed: 12691395]

29. Feldman Z, Kanter MJ, Robertson CS, et al. Effect of head elevation on intracranial pressure, cerebral perfusion pressure, and cerebral blood flow in head-injured patients. J Neurosurg 1992;76:207-11. [PubMed: 1730949]

30. Ng I, Lim J, Wong HB. Effects of head posture on cerebral hemodynamics: its influences on intracranial pressure, cerebral perfusion pressure, and cerebral oxygenation. Neurosurgery 2004;54:593-7. [PubMed: 15028132]

31. Joseph DK, Dutton RP, Aarabi B, Scalea TM. Decompressive laparotomy to treat intractable intracranial hypertension after traumatic brain injury. J Trauma 2004;57:687-93. [PubMed: 15514520]

32. North JB, Jennett S. Abnormal breathing patterns associated with acute brain damage. Arch Neurol 1974;31:338-44. [PubMed: 4411797]

33. Miller JD, Becker DP. Secondary insults to the injured brain. J R Coll Surg Edinb 1982;27:292-8. [PubMed: 7143298]

34. Caricato A, Conti G, Della CF, et al. Effects of PEEP on the intracranial system of patients with head injury and subarachnoid hemorrhage: the role of respiratory system compliance. J Trauma 2005;58:571-6. [PubMed: 15761353]

35. Albanese J, Viviand X, Potie F, et al. Sufentanil, fentanyl, and alfentanil in head trauma patients: a study on cerebral hemodynamics. Crit Care Med 1999;27:407-11. [PubMed: 10075068]

36. Dietrich WD, Alonso O, Halley M, et al. Delayed posttraumatic brain hyperthermia worsens outcome after fluid percussion brain injury: a light and electron microscopic study in rats. Neurosurgery 1996;38:533-41. [PubMed: 8837806]

37. Jones PA, Andrews PJD, Midgley S, et al. Measuring the burden of secondary insults in head-injured patients during intensive care. J Neurosurg Anesth 1994;6:4-14. 
38. Robertson CS, Clifton GL, Taylor AA, et al. Treatment of hypertension associated with head injury. J Neurosurg 1983;59:455-60. [PubMed: 6886759]

39. Biousse V, Rucker JC, Vignal C, et al. Anemia and papilledema. Am J Ophthalmol 2003;135:43746. [PubMed: 12654358]

40. Hebert PC, Wells G, Blajchman MA, et al. A multicenter, randomized, controlled clinical trial of transfusion requirements in critical care. Transfusion Requirements in Critical Care Investigators, Canadian Critical Care Trials Group. N Engl J Med 1999;340:409-17. [PubMed: 9971864]

41. Lee ST, Lui TN, Wong CW, et al. Early seizures after severe closed head injury. Can J Neurol Sci 1997;24:40-3. [PubMed: 9043746]

42. Vespa PM, Nuwer MR, Nenov V, et al. Increased incidence and impact of nonconvulsive and convulsive seizures after traumatic brain injury as detected by continuous electroencephalographic monitoring. J Neurosurg 1999;91:750-60. [PubMed: 10541231]

43. Tempkin NR, Dikmen SS, Wilensky AJ, et al. A randomized, double-blind study of phenytoin for the prevention of post-traumatic seizures. N Engl J Med 1990;323:497-502. [PubMed: 2115976]

44. Bratton SL, Chestnut RM, Ghajar J, et al. Antiseizure Prophylaxis. J Neurotrauma 2007;24 (supplement 1):S-83-S-86. [PubMed: 17511552]

45. Schramm WM, Papousek A, Michalek-Sauberer A, et al. The cerebral and cardiovascular effects of cisatracurium and atracurium in neurosurgical patients. Anesth Analg 1998;86:123-7. [PubMed: 9428865]

46. Nates JL, Cooper DJ, Day B, et al. Acute weakness syndromes in critically ill patients — a reappraisal. Anaesth Intensive Care 1997;25:502-13. [PubMed: 9352763]

47. Prielipp RC, Coursin DB, Scuderi PE, et al. Comparison of the infusion requirements and recovery profiles of vecuronium and cisatracurium 51W89 in intensive care unit patients. Anesth Analg 1995;81:3-12. [PubMed: 7598277]

48. Knapp JM. Hyperosmolar therapy in the treatment of severe head injury in children: mannitol and hypertonic saline. AACN Clin Issues 2005;16:199-211. [PubMed: 15876888]

49. Cruz J, Minoja G, Okuchi K, et al. Successful use of the new high-dose mannitol treatment in patients with Glasgow Coma Scale scores of 3 and bilateral abnormal pupillary widening: a randomized trial. J Neurosurg 2004;100:376-83. [PubMed: 15035271]

50. Cruz J, Minoja G, Okuchi K. Improving clinical outcomes from acute subdural hematomas with the emergency preoperative administration of high doses of mannitol: a randomized trial. Neurosurgery 2001;49:864-71. [PubMed: 11564247]

51. Muizelaar JP, Lutz HA, Becker DP. Effect of mannitol on ICP and CBF and correlation with pressure autoregulation in severely head-injured patients. J Neurosurg 1984;61:700-6. [PubMed: 6432972]

52. Battison C, Andrews PJ, Graham C, et al. Randomized, controlled trial on the effect of a $20 \%$ mannitol solution and a $7.5 \%$ saline/ $6 \%$ dextran solution on increased intracranial pressure after brain injury. Crit Care Med 2005;33:196-202. [PubMed: 15644669]

53. Vialet R, Albanese J, Thomachot L, et al. Isovolume hypertonic solutes (sodium chloride or mannitol) in the treatment of refractory posttraumatic intracranial hypertension: $2 \mathrm{~mL} / \mathrm{kg} 7.5 \%$ saline is more effective than $2 \mathrm{~mL} / \mathrm{kg}$ 20\% mannitol. Crit Care Med 2003;31:1683-7. [PubMed: 12794404]

54. Cooper DJ, Myles PS, McDermott FT, et al. Prehospital hypertonic saline resuscitation of patients with hypotension and severe traumatic brain injury: a randomized controlled trial. JAMA 2004;291:1350-7. [PubMed: 15026402]

55. Doyle JA, Davis DP, Hoyt DB. The use of hypertonic saline in the treatment of traumatic brain injury. J Trauma 2001;50:367-83. [PubMed: 11242309]

56. Bratton SL, Chestnut RM, Ghajar J, et al. Hyperosmolar Therapy. J Neurotrauma 2007;24(supplement 1):S-14-S-20. [PubMed: 17511539]

57. Stocchetti N, Maas AI, Chieregato A, et al. Hyperventilation in head injury: a review. Chest 2005;127:1812-27. [PubMed: 15888864]

58. Yundt KD, Diringer MN. The use of hyperventilation and its impact on cerebral ischemia in the treatment of traumatic brain injury. Crit Care Clin 1997;13:163-84. [PubMed: 9012580]

59. Muizelaar JP, van der Poel HG, Li ZC, et al. Pial arteriolar vessel diameter and CO2 reactivity during prolonged hyperventilation in the rabbit. J Neurosurg 1988;69:923-7. [PubMed: 3142972] 
60. Coles JP, Steiner LA, Johnston AJ, et al. Does induced hypertension reduce cerebral ischaemia within the traumatized human brain? Brain 2004;127:2479-90. [PubMed: 15456706]

61. Diringer MN, Videen TO, Yundt K, et al. Regional cerebrovascular and metabolic effects of hyperventilation after severe traumatic brain injury. J Neurosurg 2002;96:103-8. [PubMed: 11794590]

62. Bader MK, Arbour R, Palmer S. Refractory increased intracranial pressure in severe traumatic brain injury: barbiturate coma and bispectral index monitoring. AACN Clin Issues 2005;16:526-41. [PubMed: 16269897]

63. Schwartz ML, Tator CH, Rowed DW, et al. The University of Toronto Head Injury Treatment Study: a prospective, randomized comparison of pentobarbital and mannitol. Can J Neurol Sci 1984;11:43440. [PubMed: 6440704]

64. Ward JD, Becker DP, Miller JD, et al. Failure of prophylactic barbiturate coma in the treatment of severe head injury. J Neurosurg 1985;62:383-8. [PubMed: 3882899]

65. Eisenberg HM, Frankowski RF, Contant CF, et al. High-dose barbiturate control of elevated intracranial pressure in patients with severe head injury. J Neurosurg 1988;69:15-23. [PubMed: 3288723]

66. Messeter K, Nordstrom CH, Sundbarg G, et al. Cerebral hemodynamics in patients with acute severe head trauma. J Neurosurg 1986;64:231-7. [PubMed: 3080555]

67. Nordstrom CH, Messeter K, Sundbarg G, et al. Cerebral blood flow, vasoreactivity, and oxygen consumption during barbiturate therapy in severe traumatic brain lesions. J Neurosurg 1988;68:42431. [PubMed: 3125310]

68. Schalen W, Sonesson B, Messeter K, et al. Clinical outcome and cognitive impairment in patients with severe head injuries treated with barbiturate coma. Acta Neurochir (Wien) 1992;117:153-9. [PubMed: 1414516]

69. Sato M, Niiyama K, Kuroda R, et al. Influence of dopamine on cerebral blood flow, and metabolism for oxygen and glucose under barbiturate administration in cats. Acta Neurochir (Wien) 1991;110:174-80. [PubMed: 1927611]

70. Clifton GL, Miller ER, Choi SC, et al. Lack of effect of induction of hypothermia after acute brain injury. N Engl J Med 2001;344:556-63. [PubMed: 11207351]

71. Adelson PD, Ragheb J, Kanev P, et al. Phase II clinical trial of moderate hypothermia after severe traumatic brain injury in children. Neurosurgery 2005;56:740-54. [PubMed: 15792513]

72. Kaal EC, Vecht CJ. The management of brain edema in brain tumors. Curr Opin Oncol 2004;16:593600. [PubMed: 15627023]

73. Gudeman S, Miller J, Becker D. Failure of high-dose steroid therapy to influence intracranial pressure in patients with severe head injury. J Neurosurg 1979;51:301-6. [PubMed: 469578]

74. Saul T, Ducker T, Saleman M, et al. Steroids in severe head injury: a prospective, randomized clinical trial. J Neurosurg 1981;54:596-600. [PubMed: 7014790]

75. Edwards P, Arango M, Balica L, et al. Final results of MRC CRASH, a randomised placebo-controlled trial of intravenous corticosteroid in adults with head injury-outcomes at 6 months. Lancet 2005;365:1957-9. [PubMed: 15936423]

76. Feigin VL, Anderson N, Rinkel GJ, et al. Corticosteroids for aneurysmal subarachnoid haemorrhage and primary intracerebral haemorrhage. Cochrane Database Syst Rev 2005:CD004583. [PubMed: 16034939]

77. Marchuk G, Kaufmann AM. Spontaneous supratentorial intracerebral hemorrhage: the role of surgical management. Can J Neurol Sci 2005;32(Suppl 2):S22-30. [PubMed: 16450805]

78. Cheung A, Telaghani CK, Wang J, et al. Neurological recovery after decompressive craniectomy for massive ischemic stroke. Neurocrit Care 2005;3:216-23. [PubMed: 16377832]

79. Sahuquillo J, Arikan F. Decompressive craniectomy for the treatment of refractory high intracranial pressure in traumatic brain injury. Cochrane Database Syst Rev 2006:CD003983. [PubMed: 16437469]

80. Taylor A, Butt W, Rosenfeld J, et al. A randomized trial of very early decompressive craniectomy in children with traumatic brain injury and sustained intracranial hypertension. Childs Nerv Syst 2001;17:154-62. [PubMed: 11305769] 
81. Aarabi B, Hesdorffer DC, Ahn ES, et al. Outcome following decompressive craniectomy for malignant swelling due to severe head injury. J Neurosurg 2006;104:469-79. [PubMed: 16619648]

82. Polin RS, Shaffrey ME, Bogaev CA, et al. Decompressive bifrontal craniectomy in the treatment of severe refractory posttraumatic cerebral edema. Neurosurgery 1997;41:84-92. [PubMed: 9218299]

83. Stiefel MF, Heuer GG, Smith MJ, et al. Cerebral oxygenation following decompressive hemicraniectomy for the treatment of refractory intracranial hypertension. J Neurosurg 2004;101:241-7. [PubMed: 15309914]

84. Bor-Seng-Shu E, Hirsch R, Teixeira MJ, et al. Cerebral hemodynamic changes gauged by transcranial Doppler ultrasonography in patients with posttraumatic brain swelling treated by surgical decompression. J Neurosurg 2006;104:93-100. [PubMed: 16509152]

85. Engberg J, Oberg B, Christensen KS, et al. The cerebral arterio-venous oxygen content difference $\left(\mathrm{AVDO}_{2}\right)$ during halothane and neurolept anaesthesia in patients subjected to craniotomy. Acta Anaesthesiol Scand 1989;33:642. [PubMed: 2511726]

86. Hutchinson, PJ.; Corteen, E.; Czosnyka, M., et al. Decompressive craniectomy in traumatic brain injury: the randomized multicenter RESCUEicp study; Acta Neurochir. 2006. p. 17-20.www.RESCUEicp.com

87. Vahedi K, Hofmeijer J, Juettler E, et al. Early decompressive surgery in malignant infarction of the middle cerebral artery: a pooled analysis of three randomised controlled trials. Lancet Neurol 2007;6:215-22. [PubMed: 17303527] 
RANGEL - CASTILLO \& ROBERTSON

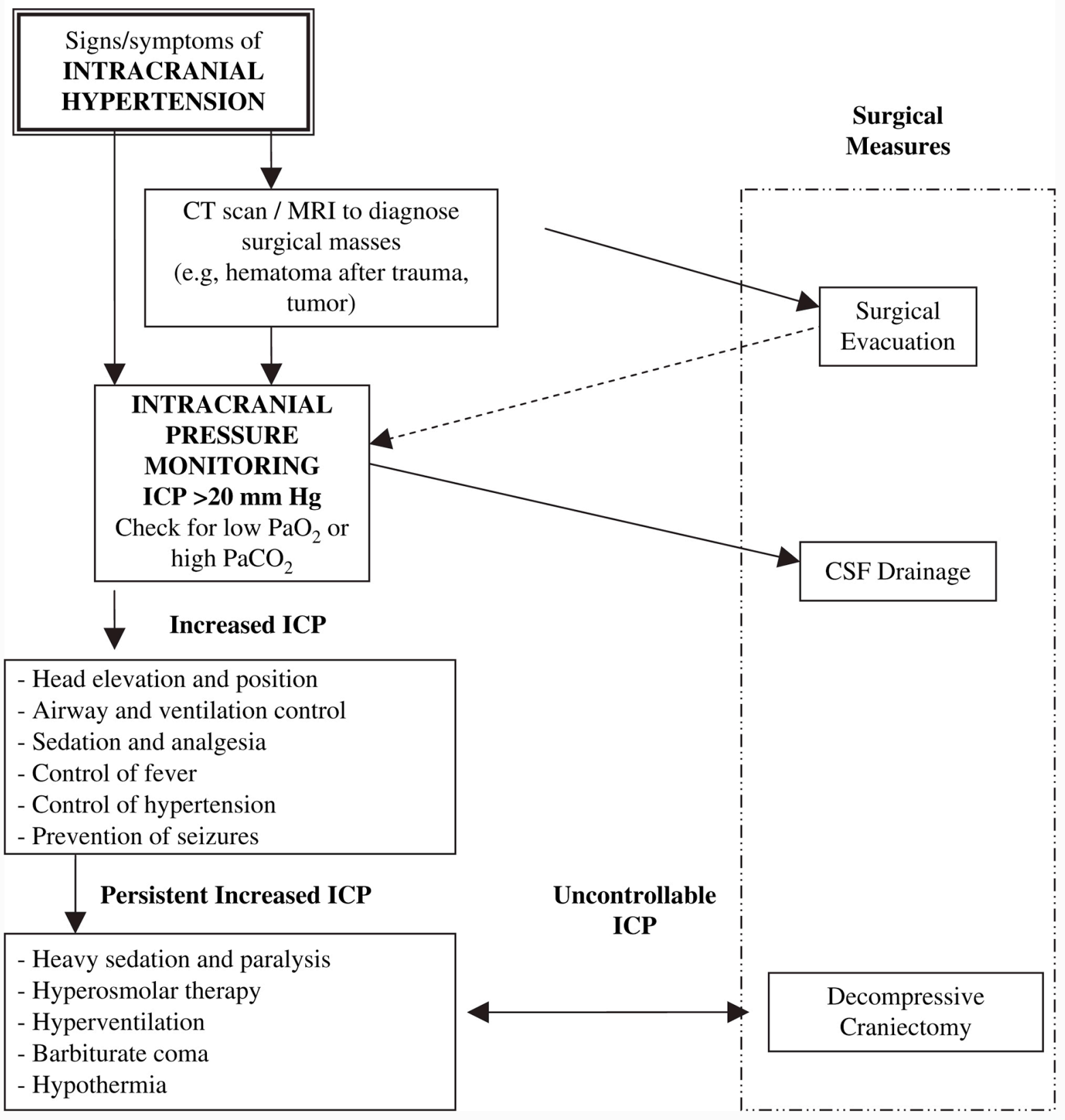

Fig. 1.

Diagram of diagnosis and treatment of intracranial hypertension. 